\title{
Another one bites the dust
}

\section{The hazards of seeking to implement reforms at universities with outstanding reputations have been demonstrated once again, this time in Switzerland.}

$\square$ witzerland's flagship university, the Swiss Federal Institute of Technology (ETH) in Zurich, is arguably the strongest in mainland Europe. The government already provides one of the highest per-capita expenditures on research in the world, and is set to increase funding by a further $30 \%$ over the next five years.

But if nothing seems to be broken, does anything need fixing? Ernst Hafen, the molecular biologist who became president of the ETH last December, thought it did. In his view, major reforms were required in order to safeguard the university's pre-eminence. Unlike most Swiss universities, where deans share decision-making, the ETH president's position is a powerful one and, in theory, Hafen should have been able to have his way.

But the ETH faculty put paid to that, pulling rank after a short but bitter public dispute and securing Hafen's resignation just eleven months in (see page 130). The hostility of the ETH faculty to the man who wanted to restructure it echoes that attracted by Larry Summers at Harvard University two years ago (see Nature 433, 190-192; 2005), which culminated in a row over his unfortunate comments on the aptitude of women and his subsequent resignation.

Hafen had been impressed by a previous, successful reorganization five years ago at the other federally funded university in Switzerland, the EFP Lausanne - the remaining universities in Switzerland are funded by their local cantons - and wanted to introduce a more corporate management model at the ETH.

The ETH currently has little hierarchy below the president, and what there is mostly concentrates in the Schulleitung, comprising the president, two vice-presidents (responsible for research and infrastructure) and the faculty-elected rector (responsible for teaching). The committee of department heads meets quarterly with the president to exchange information.

Hafen wanted to merge some departments into a less unwieldy number of schools led by professional deans. More contentiously, he sought to reform the Schulleitung, eliminating the rector's position and introducing five vice-presidents, whose arrival might have threatened the clout of senior academics.

University professors are notoriously conservative and jealous of their local powers - especially at élite institutions such as the ETH. There might therefore be a tendency to dismiss the brouhaha as academic provincialism. But this would be wrong for two reasons.

First, the ETH professors have in the recent past already cooperated with changes implemented by the president's office. That was a major reason for their reluctance this time: they are still in the process of enacting the last round of reforms, which made departments responsible for their own finances and put in place a new teaching system. They were clearly unconvinced that the time was ripe for reform of these reforms.

"Hafen wanted to introduce a more corporate

And therein lies the second reason. Hafen failed to convince the professors that his proposals made sense, and he management model at the ETH." declined to engage in the dialogue that might have won them over. Perhaps too confident of the power conferred on him on paper, he failed to talk and, fatally, he failed to listen. He pushed too fast initially and, when an impasse arose, he moved swiftly into reverse, withdrawing his whole reform package in its entirety on 23 October, thereby losing further respect.

The ETH will doubtless survive this embarrassing setback. But Hafen's departure leaves questions about whether his proposals were really being driven by the ETH supervisory council, which hired him but failed to back him when the chips were down. The council must now start afresh, by appointing a president who will inspire the confidence of the university staff.

\section{Correction or retraction?}

\section{Errors reported in this issue by authors of a Nature paper pose a dilemma about trust.}

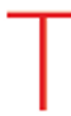
he practice of science - and the publication of science in particular - is often lauded for its capacity for self-correction, and, to a large extent, deservedly so. During the peer-review process, basic mistakes and errors of judgement are frequentlyidentified, minimizing the number that make it through into often muchimproved final publications. Erroneous results that do slip through the peer-review net may be promptly identified; if sufficiently serious, they are corrected or even withdrawn.

The reality of science publication does not always accord with such idealistic expectations, however, and the correction published this week (on page 235) is a case in point.

When an important error has been made in a published piece of work, yet the central claim or result still stands, the publication of a Corrigendum is the most sensible way forward; others are thereby alerted to any inaccuracies in the paper, which may have an impact on their own research. If, on the other hand, the errors that have been made undermine the principal message of the paper, then a retraction is in order - the paper may still contain valid scientific information, but the original publication has now lost its raison dêtre.

There is a grey area in between, exemplified by the events - past and present - that have now culminated in the aforementioned Corrigendum. The original paper (Nature 366, 143-146; 1993) is viewed by many as a landmark in its field: an experimental 'first', in which compositional analysis at atomic resolution had been achieved 
with an electron microscope. But the paper did not have an easy time with referees, with one reviewer in particular maintaining that there were "disquieting questions" over both the provenance of key data and inconsistencies in the manner in which they had been subsequently reprocessed (in response to concerns raised earlier during the review process) in order to better substantiate the central claim. The authors, however, had provided Nature with a robust defence of their work in response to these remaining criticisms - firm assurances that at the time we accepted at face value. Combined with a positive endorsement of the work that was offered by a second referee, we felt it appropriate to proceed with publication of the paper.

Seen with the benefit of hindsight, we made an error of judgement in taking those assurances on trust - perhaps influenced by our awareness of intense competition in the field at the time. For it has belatedly transpired that many of the more critical referee's "disquieting questions" did indeed have a sound technical basis, as key data were misrepresented by the authors, both during the review process and in the final published version of the paper. This has now been fully acknowledged by the authors, who say that they are mystified as to why they offered the assurances they did when originally challenged on these points.

So what does this mean for the paper? It could be argued, as we have done during extensive deliberations, that confidence in the validity of the work has been severely compromised as a consequence of these errors, and that the paper should be formally retracted. But we have concluded for several reasons that the authors' Corrigendum should be accepted. Thirteen years have elapsed since publication, and the authors no longer have available the source data to reanalyse and resubmit to peer review - and so are not in a position to mount a thorough defence of their published results against the remaining criticisms. Furthermore, an investigation commissioned by Oak Ridge National Laboratory in Tennessee has robustly cleared the authors of any intent to deceive; we have received assurances that the original data, if consistently analysed as intended, would still have supported the central thesis of the paper. And most importantly, the authors have both acknowledged and proposed corrections for their earlier mistakes.

In the end, it comes down to an issue that is at the very heart of the practice and communication of science: the question of trust. After all, if researchers and editors cannot safely assume, even as a starting point, that scientific results are essentially true as reported, then the advancement of science is in serious trouble.

Without doubt, there has been in this case a severe breach of the trust on which the publication of science is based. But the reasons underlying it, and the hypothetical outcome for the work had these concerns been tackled more robustly when first raised, can now only be speculated about. Other researchers will have their own take on the situation (see page 129).

There is some consolation in the fact that the experimental capability first reported in the flawed Nature paper was soon exceeded, as reported by these authors and others, in a range of different contexts. Thus we can at least be relieved that the progress of science was not impeded by this particular episode.

\section{Smart but lightweight}

\section{An imaginative innovation policy in Britain continues to be under-resourced.}

t is the intention of every government on Earth to inspire increased research, development and innovation in the private sector. How this should actually be done remains something of a mystery, however. Last week, the British government took a stab at the problem, announcing an administrative change that it hopes will help it meet its ambitious stated goal of expanding business expenditure on research and development from $1.2 \%$ of the economy to $1.7 \%$ by 2014 .

Innovation policy in Britain traditionally falls under the remit of the Department of Tradeand Industry (DTI), which has long housed a pot-pourri of small initiatives and programmes aimed at fostering industrial innovation. Two years ago, this mixture was placed under the guidance of the Technology Strategy Board, an advisory committee chaired by Graham Spittle of IBM.

Early next year, the Technology Strategy Board will effectively be spun off from the DTI and reconstituted as an autonomous entity. It will hire a chief executive and a small staff, and will operate at arm's length from the government, managed by a board drawing members from industry and finance. The group will be constituted much like one of the research councils that support British scientific research, but will have a different mission - fostering innovation in business.

The change will give the group more latitude for effective action, and pulling it out of the DTI will have at least two other significant advantages. It will help the committee to address innovation, not just in manufacturing industry (the DTI's traditional remit) but also in the service sector - ranging from publishing to banking - which now constitutes four-fifths of Britain's economy. And the free-standing committee will be better placed to work with all departments of government, and address the area where the state can arguably make the greatest difference of all, by supporting innovative suppliers through the $\mathrm{E} 150$ billion (US $\$ 290$ billion) or so that it spends each year on goods and services.

However, the resources under the direct control of the new body will remain, in the first instance, rather paltry. Around $£ 170$ million worth of grants and other programmes is, for all the talk about intelligent leverage, unlikely to spur much of anything across an economy the size of Britain's.

\section{"The Technology Strategy Board will be constituted much like a research council, but will have a different mission - fostering innovation in business."} The Confederation of British Industry - which has, of course, an interest in the matter - has advocated the spin-off of the Technology Strategy Board, but suggested that it needs four times as much money to have an impact. The question of additional resources will be addressed by the Treasury in next year's Comprehensive Spending Review. Its outcome will tell us how much faith the government has in this particular innovation. 